\title{
EFFECTS OF EXPLOSIVE TYPE STRENGTH TRAINING ON SELECTED PHYSICAL AND TECHNICAL PERFORMANCE CHARACTERISTICS IN MIDDLE DISTANCE RUNNING - A CASE REPORT
}

\author{
KRZYSZTOF MAĆKAŁA, ŁUKASZ JÓŹWIAK, JACEK STODÓŁKA \\ The University School of Physical Education in Wroclaw, Faculty of Physical Education, \\ Department of Athletics and Gymnastics
}

\begin{abstract}
Mailing address: Krzysztof Maćkała, Department of Athletics and Gymnastics, 35 Paderewskiego Street, 51-612 Wrocław, tel: + 4871 3473147, fax: +48 71 3473149, e-mail: krzysztof.mackala@awf.wroc.pl
\end{abstract}

\begin{abstract}
Introduction. Distance running performance is a simple function of developing high speeds and maintaining this speed as long as possible. Thus a correct running technique becomes an important component of performance. Technique is effective if the competitor can reach a better performance result with the same or lower energy consumption. The purpose of this investigation was to examine a six weeks application explosive type strength training on lower extremities power and maximum speed performance improvement in order to facilitate running technique in sub-elite male middle-distance runner. Material and methods. A sub-elite runner performed twice a week special exercises and running drills. He completed a pre and post-training jumping (SJ, CMJ, standing long jump, standing five jump) and speed (20 $\mathrm{m}$ from standing and flying start) field tests. For kinematical analysis, a video (SIMI Motion System) of a $10 \mathrm{~m}$ sprint from a $20 \mathrm{~m}$ flying start was collected. Results. Improvement occurred in all measurements but strong changes were evident in the $10 \mathrm{~m}$ from 20 flying start and in stride frequency from 3.90 to $4.01 \mathrm{~Hz}$, due to decreasing of ground contact time from 160 to $156 \mathrm{~ms}$. No strong evidence in the participant's running technique changes. Conclusion. This proved that six weeks of dynamic type strength program seems to improve neuromuscular characteristics of running speed and explosive power and no changes in running technique.
\end{abstract}

Key words: dynamic strength, sports technique, plyometrics, special tempo work, middle distance running

\section{Introduction}

The study described in this manuscript relate to one subelite middle-distance runner. This forces the reader properly analyzed the information and obtained results, in order to maintain an objective message of this manuscript.

Middle distance and long distance running performance is a simple function of developing high speeds and maintaining this speed as long as possible. Thus a correct running technique becomes an important component of performance. Technique is effective if the competitor can reach a better sports result with the same or lower energy consumption [1] The secret of the running technique lies not only in the correct structure of movements from the point of view of biomechanics but, above all, in the ability of combining the full activation of energy and maximization of muscular efforts. Both of these parameters in distance running affect the efficiency of running economy (RE). This ability may be acquired not only by mastering the form of movements but, above all, by the appropriate training, leading to their full coordination and automation [2]. However, it is difficult to point out which technique is more effective in order to guarantee the best results. From biomechanical point of view the improvement of running regardless of events (sprint, middle and long distance) will result only by increasing the speed, which heavily relay on the utilization of current running technique. It is well observed that distance runners spend more time on the ground and have deeper knee flexion during stance phase compared to sprinters at different speed $[3,4]$. It has also been known that horizontal displacement between the landing foot and center of mass (CM) during ground contact time is much longer in distance runners [3]. We also know that sprinters had much longer stride than distance and long-distance runners [3, $5,6]$. Thus the optimization of running technique is dependent on the relationship between stride length and its frequency [6, 7 , 8, 9] and specific kinematics of running stride execution [10]. However there is still relatively little know about kinematics during the footstrike that may concerns where your feet land relative to your body rather than that mid-foot runners are faster and perform better than heel-strike runners. We want to know which of theses factors the most determine the running economy, and first of all how these factors directly facilitate faster running.

Strength and power training in its various forms has been used successfully by sprinters, jumpers, throwers, and powerrelated sporting events to increase performance via changes in the neuro-muscular system $[11,12,13,14,15,16,17]$. The question is, how much does explosive type strength training improve lower extremities power and speed performance in endurance sports, especially in running? Application of strength training (both explosive-type and high resistance in distance running) is not a new concept and is quite often used in performance improvement [18, 19, 20, 21, 22]. In most cases it is closely related to the running economy (RE), which can be defined as the oxygen consumption (VO2max) and running velocity (10). Research has identified several factors that may be associated with RE. They can be divided into two main groups: physiological and muscle/mechanical [23, 24, 25]. Research indicates that anaerobic power and muscular strength may be important for improvement of running performance through muscular and neurological changes [26, 27, 28]. Neural adaptations may be connected 
with motor unit recruitment and synchronization, progress, what increase the force development rate via improvement in the stretch-shortening cycle $[26,27,19]$. In contrast to these changes the muscular adaptation may increased force production, intramuscular glycogen or made some changes in anaerobic enzyme activity [28, 26]. Therefore the muscular and neurological changes may really challenges the improvements and should enhance running performance and all are becoming important performance predictors [29, 30, 19].

The practical question being addressed is does the efficacy of special type strength training cause middle distance runner to improve its physical and technical abilities? Therefore first it is necessary to examine the direct effect of the application of these type of training in order to improve the lower extremities power. Then how does this increase of power relate to several kinematic parameters of maximum running speed, and which of these variables has a direct impact on the speed improvement. According to these statements we are able to confirm that the practical question of the nature of this study is contained in the description of the purpose of this report. The purpose of this investigation was to examine a six weeks of combine dynamic strength and plyometric intervention program on lower extremities power and maximum speed performance improvement in male middle-distance runner. A secondary purpose was to examine the potential connection between improvement of maximum speed and explosive power in order to facilitate running technique. Based on these assumptions we are able to formulate our hypothesis: is that improvement in kinematical measures of a single running step executed at maximum speed (the utilization of stored elastic energy in muscles after plyometric training) can be demonstrated concomitant with some changes of current athlete running technique.

\section{Material and methods}

This single subject study utilised $(n=1)$ a male, sub-elite (masterclass) middle-distance runner ( 27 years old, $64 \mathrm{~kg}$ body mass, $180 \mathrm{~cm}$ height) with personal best results of $800 \mathrm{~m} \mathrm{-}$ $1^{\prime} 47.96$ and $1500 \mathrm{~m}-3^{\prime} 44.04$. He is medalist of indoor and outdoor Polish Championships in Athletics. This subject volunteered for the six week study during end of special preparation II and pre-competition phase (spring) of yearly training schedule. The six week training duration was chosen because the authors hypothesised that both neural and muscular adaptation toward special dynamic strength exercises may occur within the six week time frame. During the experiment, the runner participated in all scheduled training activities and has not suffered any injury. The participant was informed of the protocol and procedure of the experiment prior to the exercise. Written consent to participate was obtained. The study was approved by the Human Ethics Committee of the University School of Physical Education in Wroclaw.

\section{Dynamic strength and plyometric intervention programme}

In addition to the regular training schedule, the runner was assigned a twice a week (Monday and Wednesday) dynamic strength and plyometric programme. Each training session combined: a) lower body dynamic exercises (fig. 1) executed in the following order: split legs jumps on the box, upward jump with slightly straddled legs, step-ups with front leg swing, toe rising from a half-squat, and alternate lunges; and b) special plyometric drills executed in the following order: power skip "A", alternate sprint bounding, and power skip "C" (tab. 1). Plyometric exercises were chosen because they are specific to the running action in terms of both movement structure and the velocity of execution. Exercises 1, 2, 3, and 5 have a nature of eccentric work and build up the speed capabilities of a runner. In this case it might be assumed that the basis of the amount of load is about $1 / 3$ of the competitor's weight. Exercise 4 is to develop muscular power and the nature of work is concentric. The subject performed all exercises in a dynamic manner. In order to adapt to the neural stress and avoid injury, the entire training programme progressed in a periodised manner from period one (weeks one to three) to period two (weeks four to five) and period three (week six). The video recording of proper execution (technique) of these exercises took place in a weight room (fig. 1).
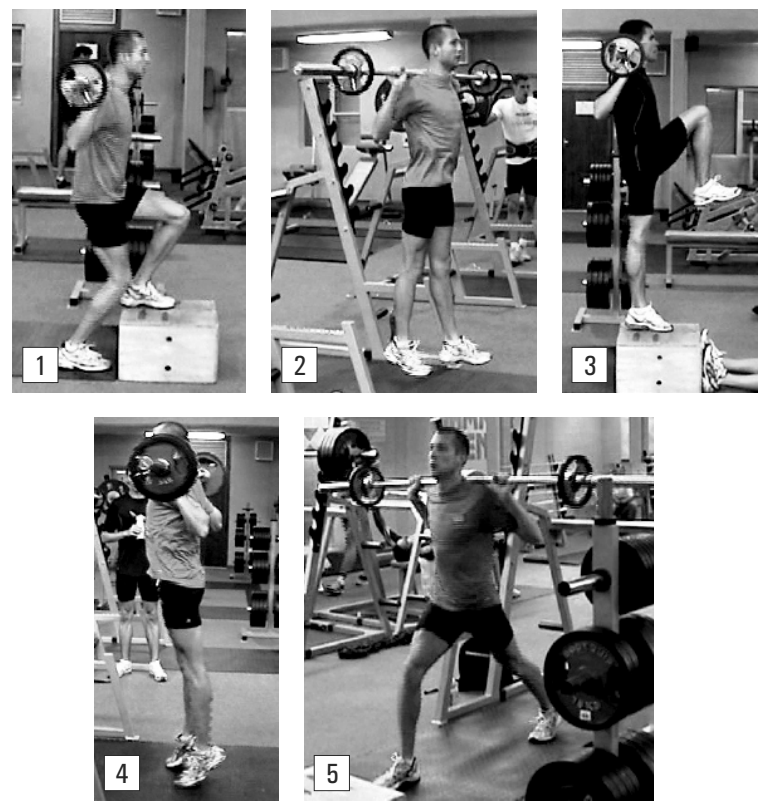

Figure 1. The lower body dynamic strength exercises executed in the following order: (1) split legs jumps on the box, (2) upward jumps with slightly straddled legs, (3) step-ups with front leg swing,

(4) toe rising from a half-squat, (5) alternate lunges

Table 1. Summary of special dynamic strength exercises training programme

\begin{tabular}{|c|c|c|c|c|}
\hline \multicolumn{5}{|c|}{ Dynamic strength and plyometric exercises programme } \\
\hline Weeks & Exercise & Sets & Reps & Load (kg/m) \\
\hline \multirow[t]{2}{*}{1.3} & $\begin{array}{l}\text { Split legs jumps on the box } \\
\text { Upward jumps with slightly straddled legs } \\
\text { Step-ups with front leg swing } \\
\text { Toe climbing from a half-squat } \\
\text { Alternate lunges }\end{array}$ & $\begin{array}{l}3 \\
3 \\
3 \\
4 \\
3\end{array}$ & $\begin{array}{l}20 \\
20 \\
12 \\
10 \\
30\end{array}$ & $\begin{array}{l}20 \mathrm{~kg} \\
20 \mathrm{~kg} \\
20 \mathrm{~kg} \\
60 \mathrm{~kg} \\
20 \mathrm{~kg}\end{array}$ \\
\hline & $\begin{array}{l}\text { Power skipping (skip A) } \\
\text { Alternate sprint bounding } \\
\text { Power skipping (skip C) }\end{array}$ & $\begin{array}{l}2 \\
2 \\
2\end{array}$ & : & $\begin{array}{l}20 \mathrm{~m} \\
30 \mathrm{~m} \\
20 \mathrm{~m}\end{array}$ \\
\hline \multirow[t]{2}{*}{$4-5$} & $\begin{array}{l}\text { Split legs jumps on the box } \\
\text { Upward jumps with slightly straddled legs } \\
\text { Step-ups with front leg swing } \\
\text { Toe climbing from a half-squat } \\
\text { Alternate lunges }\end{array}$ & $\begin{array}{l} \\
3 \\
3 \\
3 \\
5 \\
3\end{array}$ & $\begin{array}{l}20 \\
20 \\
12 \\
10 \\
30\end{array}$ & $\begin{array}{l}25 \mathrm{~kg} \\
25 \mathrm{~kg} \\
25 \mathrm{~kg} \\
60 \mathrm{~kg} \\
25 \mathrm{~kg}\end{array}$ \\
\hline & $\begin{array}{l}\text { Power skipping (skip A) } \\
\text { Alternate sprint bounding } \\
\text { Power skipping (skip C) }\end{array}$ & $\begin{array}{l}3 \\
3 \\
3\end{array}$ & : & $\begin{array}{l}20 \mathrm{~m} \\
30 \mathrm{~m} \\
20 \mathrm{~m}\end{array}$ \\
\hline \multirow[t]{2}{*}{6} & $\begin{array}{l}\text { Split legs jumps on the box } \\
\text { Upward jumps with slightly straddled legs } \\
\text { Step-ups with front leg swing } \\
\text { Toe climbing from a half-squat } \\
\text { Alternate lunges }\end{array}$ & $\begin{array}{l}2 \\
2 \\
2 \\
3 \\
2\end{array}$ & $\begin{array}{l}20 \\
20 \\
15 \\
10 \\
30\end{array}$ & $\begin{array}{l}30 \mathrm{~kg} \\
30 \mathrm{~kg} \\
30 \mathrm{~kg} \\
65 \mathrm{~kg} \\
30 \mathrm{~kg}\end{array}$ \\
\hline & $\begin{array}{l}\text { Power skipping (skip A) } \\
\text { Alternate sprint bounding }\end{array}$ & $\begin{array}{l}2 \\
2\end{array}$ & $\cdot$ & $\begin{array}{l}20 \mathrm{~m} \\
30 \mathrm{~m}\end{array}$ \\
\hline
\end{tabular}




\section{Lower extremity explosive jumping ability measurement}

The runner completed a battery of four pre- and post-tests at the beginning and end of the study (week 6). The explosive power of the lower extremities was assessed by means of two vertical jumps: squat jump (SJ) and countermovement jump (CMJ). The participant must jump as high as possible snapping the horizontal vanes (each $0.5 \mathrm{~cm}$ ) using the Vertical Jump Measuring Device (Polsport, Poland). The measured distance was between the standing reach height and the maximum jump height. In addition, two horizontal jumps - standing long jump (SLJ) and standing five jumps (SFJ) - were applied where the participant attempts to jump as far as possible, landing on both feet without falling backward using landing mats (Polsport, Poland). The measurement is taken from the take-off line to the nearest point of contact on the landing (back of the heels) after one jump (SLJ) and after five jumps (SFJ). The average of three attempts was used for data analysis.

\section{Kinematics of maximum speed measurement}

To determine maximum velocity, two sprint runs were performed. After a standardised warm up, the athlete ran $20 \mathrm{~m}$ and $50 \mathrm{~m}$ from a standing start. Two (customised) photocells were used for timing. The first was placed directly in front of the front foot at the ground level. The second photocell was at the finish line. The time starts as the sprinter passes the first photocell and stops when he passes the finish line photocell. For data analysis the average of three attempts of $20 \mathrm{~m}$ and two attempts of $50 \mathrm{~m}$ were used. A video recording of a $10 \mathrm{~m}$ sprint from a $20 \mathrm{~m}$ flying start during $200 \mathrm{~m}$ tempo repetition was taken using the SIMI Motion System (SIMI Reality Motion Systems GmbH, Germany) from one digital video camera (Panasonic VC 210/Full HD) set at $50 \mathrm{~Hz}$, then analysed frame-by-frame. The camera was placed perpendicular to the running direction in the $10 \mathrm{~m}$ interval, then between 150 and $160 \mathrm{~m}$ along the track. The $20 \mathrm{~m}$ flying mark was used to force the runner to change speed in order to reach the highest possible value during the $10 \mathrm{~m}$ sprint. The pretraining measurement took place during the first of ten $200 \mathrm{~m}$ repetitions $(26.05 \mathrm{~s})$. The target time for this tempo was $27.0 \mathrm{~s}$ $(13.5$ per $100 \mathrm{~m})$. In turn, the post-training measurement was also taken during the first of four $200 \mathrm{~m}$ repetitions (24.69 s). This time the target was $26.0 \mathrm{~s}$ (13.0 s per $100 \mathrm{~m}$ ). The average time of four $200 \mathrm{~m}$ repetitions was $24.90 \mathrm{~s}$. The frame-by-frame analysis of the $10 \mathrm{~m}$ recording allowed to distinguish the following kinematics parameters: $10 \mathrm{~m}$ flying time, $10 \mathrm{~m}$ speed $(\mathrm{m} / \mathrm{s})$, $10 \mathrm{~m}$ - stride number, $10 \mathrm{~m}$ - stride frequency (Hz), $10 \mathrm{~m}$ - stride length (m), and $5 \mathrm{~m}$ contact time (ms).

\section{Special tempo running programme}

After completing two sessions of dynamic strength workouts and special plyometric drills (Monday and Wednesday), the runner performed a separate periodised session (Friday) of special endurance tempo workout. The participant performed two series of 5 repetitions of $200 \mathrm{~m}$ at $13.5 \mathrm{~s}$ per $100 \mathrm{~m}$ in weeks one to three, then 4 to 6 reps at $13.0-13.5 \mathrm{~s}$ in weeks four to five, and 3 to 4 reps at $12.8 \mathrm{~s}$ in week six. The main principle of application of this type of training was to perform work in the mixed (aerobic-anaerobic) energy zone at the beginning of the six week programme, and then move to a predominantly anaerobic zone in the last two to three weeks. In addition, after each $200 \mathrm{~m}$ repetition the heart rate was recorded using a heart rate monitor-Polar RS300X GPS (Finland).

\section{Statistical analysis}

Statistics included the calculation of mean and standard deviation (SD). All data were analysed using the statistics package for Windows Statistical Package for Social Science (version 11.0, Chicago Il.).

\section{Results}

Table 2 shows the pre-test and post-test mean values for the selected speed and explosive ability measurement, including $20 \mathrm{~m}$ and $50 \mathrm{~m}$ from a standing start, SJ, CMJ, SLJ, and SFJ. Improvement occurred in almost all measurements of physical fitness (SJ, CMJ, $20 \mathrm{~m}$, and $50 \mathrm{~m}$ from a standing start, respectively $7.1 \%, 11.7 \%, 6.7 \%$, and $4.5 \%$ ). The $10 \mathrm{~m}$ running speed improvements of $0.4 \mathrm{~s}(3.5 \%)$ were derived from an increase of stride frequency from 3.90 to $4.01 \mathrm{~Hz}$ (about $2.8 \%$ ), and due to decreased ground contact time from 160 to 156 ms (approximately $2.4 \%$ ). No changes particularly affect stride length - increase of $2 \mathrm{~cm}(0.9 \%)$.

Table 2. Characteristics of selected speed, explosive ability and kinematic parameters of $10 \mathrm{~m}$ from $20 \mathrm{~m}$ flying start measurement

\begin{tabular}{|l|c|c|c|c|c|}
\hline \multirow{2}{*}{\multicolumn{1}{|c|}{ Variables }} & \multicolumn{2}{|c|}{ Pre-training } & \multicolumn{2}{c|}{ Post-training } & Difference \\
\cline { 2 - 6 } & $\mathrm{x}$ & $\mathrm{SD}$ & $\mathrm{x}$ & $\mathrm{SD}$ & $\%$ \\
\hline 20 m standing start (s) & 3.12 & 0.05 & 2.91 & 0.04 & 6.7 \\
50 m standing start (s) & 6.28 & 0.01 & 6.00 & 0.12 & 4.5 \\
Squat jump (SJ) (cm) & 31.10 & 1.63 & 33.71 & 1.04 & 7.1 \\
Vertical jump (CMJ) (cm) & 41.33 & 1.26 & 46.16 & 2.47 & 11.7 \\
Standing long jump (SLJ) (m) & 2.31 & 0.06 & 2.47 & 0.06 & 6.9 \\
Standing five jumps (SFJ) (m) & 12.06 & 0.12 & 12.34 & 0.14 & 2.3 \\
\hline \hline $10 \mathrm{~m}$ time (s) & 1.19 & - & 1.15 & - & 3.5 \\
$10 \mathrm{~m}$ velocity (m/s) & 8.40 & - & 8.69 & - & 3.4 \\
$10 \mathrm{~m}$ - stride number & 4.65 & - & 4.61 & - & 0.8 \\
$10 \mathrm{~m}$ - stride frequency (Hz) & 3.90 & - & 4.01 & - & 2.8 \\
$5 \mathrm{~m}$ contact time (ms) & 160 & - & 156 & - & 2.5 \\
$10 \mathrm{~m}$ - stride length (m) & 2.15 & 0.008 & 2.17 & 0.007 & 0.9 \\
\hline
\end{tabular}

Analysis of the post-training data (tab. 3) showed a trend suggesting strong improvement in special endurance tempo work. Taking into account the large number of repetitions (6 to 8), the short breaks between repetitions ( $4 \mathrm{~min}$.), and the intensity of training (85-90\% of maximum taken from his $200 \mathrm{~m}$ best performance), the athlete ran all $200 \mathrm{~m}$ repetitions faster than the target

Table 3. Characteristics of intensive tempo running programme

\begin{tabular}{|c|c|c|c|c|c|c|c|c|c|c|c|}
\hline \multirow{2}{*}{ Weeks } & \multirow{2}{*}{ Distance } & \multirow{2}{*}{ Sets } & \multirow{2}{*}{ Reps } & \multicolumn{2}{|c|}{ Break between (min.) } & \multirow{2}{*}{$\begin{array}{c}200 \mathrm{~m} \\
\text { target time }(\mathrm{s})\end{array}$} & \multicolumn{2}{|c|}{$200 \mathrm{~m}$ time (s) } & \multirow{2}{*}{$\begin{array}{c}\text { Target } \\
\text { heart rate }\end{array}$} & \multicolumn{2}{|c|}{ Heart rate } \\
\hline & & & & reps & sets & & $x$ & SD & & $x$ & SD \\
\hline 1 & $200 \mathrm{~m}$ & 2 & 5 & 3 & 6 & 27.0 & 26.95 & 0.34 & 160 & 163.60 & 2.12 \\
\hline 2 & $200 \mathrm{~m}$ & 2 & 5 & 3 & 6 & 27.0 & 27.06 & 0.19 & 160 & 161.90 & 2.92 \\
\hline 3 & $200 \mathrm{~m}$ & 2 & 5 & 3 & 6 & $27.0-26.5$ & 26.91 & 0.17 & 160 & 162.70 & 2.63 \\
\hline 4 & $200 \mathrm{~m} ?$ & 2 & 4 & 3 & $6-8$ & $26.5-26.0$ & 25.84 & 0.29 & $165-170$ & 167.25 & 3.06 \\
\hline 5 & $200 \mathrm{~m}$ & 2 & 4 & $3-4$ & $6-8$ & $26.5-26.0$ & 25.35 & 0.21 & $165-170$ & 168.28 & 2.05 \\
\hline 6 & $200 \mathrm{~m}$ & 2 & 3 & 3.4 & 8 & $26.0-25.5$ & 24.90 & 0.16 & $175-180$ & 172.83 & 2.64 \\
\hline
\end{tabular}


time with an average of 0.6 to $0.7 \mathrm{~s}(2.5 \%)$.

Figure 2 shows the mean values of selected kinematic variables of the subject's running stride of a $10 \mathrm{~m}$ flying sprint the moment between $150 \mathrm{~m}$ and $160 \mathrm{~m}$ of $200 \mathrm{~m}$ repetition. The first picture (a) represents the early stance of the support phase. The distance between the first contact point (hill) and projection of center of gravity CG is about $93 \mathrm{~cm}$. The distance of $35 \mathrm{~cm}$ and angle of 81 s at a footstrike are similar to the other corresponding values. However, the runner is landing more on the heel than mid-foot. The angle between thigh and shank is $96^{\circ}$. The main amortisation phase (picture b) shows a significant lowering of the hip, which moves the centre of gravity towards an undesirable lower position. The angle between the trunk and the thigh of the support leg is reflected in a narrow angle of approximately 112 s, and the angle between trunk and thigh is about $126^{\circ}$, which indicates a lower position of the hip. Picture (c) underlines a dynamic take-off with a highlighted knee drive forward and upward. The take-off angle of 64ş (the angle between shank and the ground) corresponds with other athletes' measurements. The distance between take-off place and the pro-jection of CG is about $48 \mathrm{~cm}$. The angle between trunk and thigh of the driving leg is about $99^{\circ}$, which indicates the dynamic ac-tion of knee driving. The arms too show a large degree of move-ment, which can result in an increase in energy expenditure and disturbances in the economy of running (picture c). The angle between arms and forearms is about 83ş and corresponds to the value of current running technique.
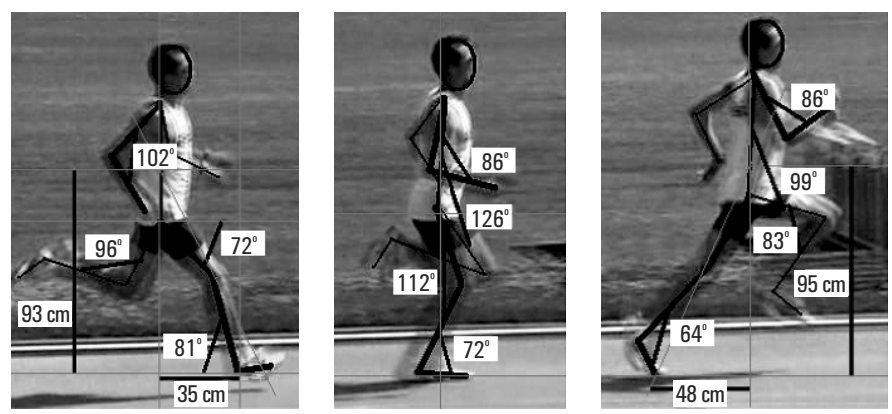

Figure 2. Means value of selected working angels (pre-training and post-training) of stride sequence when running with maximal speed over a $10 \mathrm{~m}$ flying sprint

\section{Discussion}

The purpose of this investigation was to examine a six weeks application of explosive type strength training on lower extremities power and maximum speed performance improvement in order to facilitate running technique in sub-elite male middledistance runner. The utilisation of stored elastic energy in muscles after plyometric training should relate to changes of kinematics of running strides - stride length and stride frequency. The reduction of ground contact time will improve the efficiency of running technique (RT) and indirectly increase maximum running speed.

The main focus in middle distance training should be given to accounting for intra-individual variability in changing the current pattern of running technique (RT) via application of explosive type of strength. The literature has well documented that explosive strength and speed training supplemented by special support running exercises of a dynamic character has a positive impact on the neuromuscular system. It can increase the runner's ability for explosive force production (rate of force development), rate of motor unit activation, and an improvement of an athlete's anaerobic energy production. Supporting evidence of these changes can be seen in extensive research done by Paavolainen et al. [19], who studied the effect of explosive strength training on running performance. In this study the runners were able to significantly improve their $5 \mathrm{~km}$ performance. In another investigation, Sinnett et al. [31] concluded that a strong relationship exists between explosive strength and $10 \mathrm{~km}$ performance. Similar to these two groups of researchers, Turner et al. [21] investigated the influence of a six week plyometric programme on RE improvement. They found that this type of training modalities improved RE by $2-3 \%$. According to Spurrs et al. [20] six weeks of explosive type strength training have a strong impact on improvement in CMJ height and fivebound test in conjunction with a $2.7 \%$ improvement in $3 \mathrm{~km}$ running performance. Saunders et al. [22] found that plyometric training (nine weeks of application) resulted in RE improvement, with the likely mechanisms residing in the muscle, or alternatively by improving running mechanism in highly-trained distance runners.

The results of measuring post-training physical abilities show an improvement in most of the dynamic parameters - SJ, CMJ, SLJ, SFJ. In our study the maximal CMJ height showed a much bigger improvement than SJ by about $4.6 \%$. This confirms the assumption that stretch-shorten cycle (SSC) potentiation of concentric contraction is much stronger in CMJ than in SJ. However, some earlier studies reported an inverse relationship [32, 33]. The improvement can be explained by noting that dynamic strength training combined with a plyometric programme was extremely intense (twice a week as independent training section) and aimed at both vertical and horizontal jumps. This improvement provides a higher level of power generated by the lower limbs. However, this did not translate into a significant increase in stride length, which only improved by $0.9 \%$. Therefore, the strong increased frequency of stride $(2.8 \%)$, which is a specific expression of ground contact time reduction during support phase, resulted in an increase of speed. This suggests that explosive power exercises and plyometrics, via movement that involves the SSC, can substantialy improve the ability of muscles to store and return elastic energy.

According to Cornu et al. [34], there are many structures that can be positively changed as a result of plyometric training application, such as contractile components and the series of elastic components (SEC). However, it is the musculotendinous system (MTS) that may determine the runner's ability to store and utilise the elastic energy [34, 20, 24, 25, 35]. Following Spurrs's et al [20] thoughts, we can suppose that stiffer musculotendinous units will cause greater lengthening of the contractile component, which in turn facilitate the production of force through improved length tension and force velocity conditions. This is an extraordinary requirement for speed improvement by shortening ground contact time and facilitating quicker execution of a single stride. If we multiply it by multiples of a singlestep execution on the specified distance (example intensive tempo), we get significant improvements in time by the economisation of the running structure [36].

There has been no too much differences in the values of selected kinematic variables recorded in pre-training and posttraining measurements. Therefore it was difficult to explicitly state that there was an improvement in the subject's running technique (RT) after six weeks of dynamic strength and special plyometric programme application. Figure 2 presents the mean values of selected angles between the segments of the body. An important factor of any efficient RT is a support phase which should generate as little speed decrease as possible. It can be achieved by a fast execution of this movement through landing on the middle-foot. According to Noakes [37] and Cavanagh [38], the runner with poorer economy may be connected with muscles that are less able to utilise the impact energy produced as they eccentrically absorb the force of landing. When viewing the sequence of pictures (1), the runner is landing on the typical 
middle-foot strike, rather than the heel. This probably contributed to reduction of the support phase (ground contact time decrease about $2.4 \%$ ). Such improvement depends largely on how the runner plants his/her foot on the ground, and therefore how he/she is distributing the support phase time. In turn, this affects the running speed. This design was to force the runner to change from landing on the heel to landing on the middle-foot as required. Practice has shown that this is very difficult to implement technically. Apparently, a lack of such a motion structure can provide information that a $10 \mathrm{~m}$ sprint is not enough to change the way of a foot plant. The explanation might be that the $20 \mathrm{~m}$ flying start took place during the $200 \mathrm{~m}$ repetition, not as a single $10 \mathrm{~m}$ sprint test. From a practical and mechanical point of view the improvement in middle and long distance running can only be possible by keeping an optimal stride length (individual value) leading to maintaining an external structure of running movement and an increase in frequency by reducing the time of the support phase. This assumption is fully proven in our study.

In our study we did not measure a single performance improvement - e.g. $1 \mathrm{~km}, 3 \mathrm{~km}, 5 \mathrm{~km}$ - as other authors [19, 20, 25, 21]. In spate of that, after the end of the experiment in the second week of pre-competition period, the athlete ran a $600 \mathrm{~m}$ test and reached 1:18.92 $\mathrm{s}$. This is a good time, which can predict the results in the range of 1:48.00 in the 800 meters performance. However during six weeks of the dynamic type strength application we control the runner's intensive tempo (IT) workout. The term intensive tempo training refers to exercise at 8090\% (HR 160-180) intensity, a smooth and controlled repetition runs. Its progressively increasing intensity is prerequisite work into special and speed endurance sessions. The single $200 \mathrm{~m}$ unit measurement gives a measurable and visible result. Taking into account the periodised number of repetitions (10-8, 8-6, 64 ), the short breaks between repetitions (4 min.), and the intensity of training (85-90\% of maximum taken from the subject's $200 \mathrm{~m}$ best performance), the runner ran all $200 \mathrm{~m}$ repetitions faster than the target time with an average of 0.6 to $0.7 \mathrm{~s}(2.5 \%)$.

The results of this investigation have shown that a six week programme of dynamic strength and support plyometrics led to improvements in all measurements of physical fitness with significant changes in running speed. This proved that a dynamic strength and plyometric programme seems to improve neuromuscular characteristics of running speed by increasing the ability to utilise the energy stored in muscle structures. We can also assume that there has been some optimisation of running technique (RT) by reducing the time of single stride execution. From a practical standpoint, this study provides support for the application of six weeks (twice per week) of special type strength training in order to improve explosive power and speed abilities. Additionally, the final thoughts should not be generalized because of study limitation. This case report has illustrated some trends in middle distance training, however needs to be restricted to the conditions related to this particular runner. The study should be repeated or continued among bigger group where runners demonstrate a varying performance level.

\section{Conclusions}

The study only partially proved our hypothesis, that the six weeks of utilization of stored elastic energy in muscles after dynamic type strength and plyometric training can influenced in changes of current athlete running technique. Kinematic analysis (mean angle values) of running technique (RT) in the different phases of a single running step performed during the $10 \mathrm{~m}$ sprint in pre-training and post-training measurements showed no significant changes. However the running speed improvements were derived from an increase of stride frequency from 3.90 to $4.01 \mathrm{~Hz}$, due to a decreased ground contact time from 160 to $156 \mathrm{~ms}$, which is one of the parameters that have a direct impact on running technique.

\section{Literature}

1. Yasushi E., Michiyoshi A., Hidetaka O., Norihisa F. (1999). Running technique in long distance running and the effectiveness of mechanical energy utilization. Japanese Journal of Biomechanics in Sports \& Exercise 3(1) 12-19.

2. Williams K.R., Cavanagh P.R., Ziff J.L. (1991). Biomechanical studies of elite female distance runner. International Journal of Sports Medicine 8(2), 107-118.

3. Bushnell T., Hunter I. (2007). Differences in technique between sprinters and distance runners at equal and maximal speeds. Sports biomechanics 6(3), 261-268.

4. Novacheck T.F. (1998). The biomechanics of running. Gait Posture 7(1), 77-95

5. Nummela A., Rusko H., Mero A. (1994). EMG activities and ground reaction force during fatigued and nonfatigued sprinting. Medicine and Science in Sports and Exercises 26(5), 605609.

6. Cavanagh P.R., Kram R. (1990). Stride length in distance running: velocity, body dimensions, and added mass effects. In P.R. Cavanagh (ed.), Biomechanics of distance running (pp. 35-63). Illinois: Human Kinetic Books.

7. Brüggemann G.P., Koszewski D., Müller H. (1997). Biomechanical research project: Athens 1997, final report. Oxford: Meyer \& Meyer Sport, 12-41.

8. Coh M., Dolenec A., Jost B. (1998). Kinematic and dynamic structure of the sprinting stride of top female sprinters. Biology and Sport 4, 237-243.

9. Mackala K. (2007). Optimisation of performance through kinematic analysis of the different phases of the 100 meters. New Studies in Athletics 22, 7-16.

10. Enomoto Y., Kadano H., Suzuki Y., Chiba T., Koyama K. (2008). Biomechanical analysis of the medalists in the 10,000 meters at the 2007 World Championships in Athletics. New Studies in Athletics 3, 61-66.

11. Schmidtbleicher D. (1985). Strength training. Part 1. Classification of methods. Sports: Science Periodical on Research and Technology in Sport 8, 1-8.

12. Radford P.F. (1990). Sprinting. In T. Reilly, N. Secher, P. Snell, C. Williams (eds.), Physiology of Sport (pp.71-99). London: E. \& F.N. Spon.

13. Mero A., Komi P.V., Gregor R.J. (1992). Biomechanics of sprint running. Sport Medicine 13, 376-392.

14. Siff M.C., Verkhoshansky Y.V. (1996). Supertraining: special strength training for sporting excellence. Pittsburgh: Sports Support Syndicate.

15. Martin D.E., Coe P.N. (1997). Better training for distance runners. Human Kinetics, Ilinois: Champaign.

16. Hakkinen K., Alen M., Kraemer W.J., Gorostiga E., Izquierdo M. et al. (2003). Neuromuscular adaptations during concurrent strength and endurance training versus strength training. European Journal of Applied Physiology 89, 42-52.

17. Weyannd P.G., Sternlight D.B., Bellizzi M.J., Wright S. (2001). Faster top running speeds are achieved with greater ground forces not more rapid leg movement. Journal of Applied Physiology 89(5), 1991-1999.

18. Johnston R.E., Quinn T.J., Kertzer V., Vroman N.B. (1997). Strength training in female distance runners: impact on running economy. Journal of Strength and Conditioning Research 11, 224-229.

19. Paavolainen L., Hakkinen K., Hamalainen A., Nummela A., Rusko H. (1999). Explosive-strength training improves 5-km running time by improving economy and muscle power. Jour- 
nal of Applied Physiology 86, 1527-1533.

20. Spurrs R.W., Murphy A.J., Watsford M.L. (2003). The effect of plyometric training on distance running performance. European Journal of Applied Physiology 89(1), 1-7.

21. Turner A.M., Owings M., Schwane J.A. (2003). Improvement in running economy after 6 weeks of plyometric training. Journal of Strength Conditioning Research 17(1), 60-67.

22. Saunders P.H., Telford R.D., Pyne D.B., Petola E.M., Cunningham R.B. et al. (2006). Short - term plyometric training improves running economy in highly trained middle and long distance runner. Journal of Strength and Conditioning Research 20(4), 947-954.

23. Daniels J. (1985). A physiologist's view of running economy. Medicine Science of Sports and Exercises 17, 322-338.

24. Dalleau G., Belli A., Bourdin M., Lacour J.R. (1998). The spring-mass model and the energy cost on treadmill running. European Journal of Physiology 77, 257-263.

25. Dumke C.L., Pfaffenroth C.M., McBride J.M., McCauley G.O. (2010). Relationship between muscle strength, power and stiffness and running economy in trained male runners. International Journal of Sports Physiology and Performance 5, 249-261.

26. Kraemer W.J., Deschenes M.R., Fleck S.J. (1988). Physiological adaptations to resistance exercise. Implications for athletic conditioning. Sports Medicine 6, 246-256.

27. Sale D.G. (1988). Neural adaptation to resistance training. Medicine and Science in Sports and Exercise 20, 135-145.

28. Abernethy P.J., Jurimae J., Logan P.A., Taylor A.W., Thayer R.E. (1994). Acute and chronic response of skeletal muscle to resistance exercise. Sports Medicine 17, 22-38.

29. Tanaka H., Swensen T. (1998). Impact of resistance training on endurance performance. A new form of cross-training? Sports Medicine 25, 191-200.

30. Conley D.L., Krahenbuhl G.S. (1980). Running economy and distance running performance of highly trained athletes. Medicine Science of Sports and Exercises 12, 357-360.
31. Sinnett A.M., Berg K., Latin R.W., Noble J.M. (2001). The relationship between field tests of anaerobic power and $10 \mathrm{~km}$ run performance. Journal of Strength and Conditioning Research 15(4), 405-412.

32. Komi P.V. (1984). Physiological and biomechanical correlates of muscle functions: Effects of muscle structure and stretch-shortening cycle on force and speed. In R.I. Terjung (ed.), Exercises and Sport Science Reviews (pp. 81-121). Lexington: MA Collamore Press

33. Anderson F.C., Pandy M.G. (1993). Storage and utilization of elastic energy during jumping. Journal of Biomechanics 26, 1413-1427.

34. Cornu C., Almeida Silveria M.I., Goubel F. (1997). Influence of plyometric training on the mechanical impedance of human ankle joint. European Journal of Applied Physiology 76, 282-288.

35. Kyrolainen H., Kivela R., Koskinen S. (2003). Interrelationship between muscle structure, muscle strength and running economy. Medicine Science of Sports and Exercises 35, 41-45.

36. Scholz M.N., Bobert M.F., van Soest A.J., Clark J.R., van Heerden J. (2006). Running biomechanics: Shorter heels, better economy. Journal of Experimental Biology 211, 3266-3271.

37. Noakes T. (1991). Lore of running. Leisure Press. Illinois: Champaign:

38. Cavanagh P.R. (1987). The biomechanics of lower extremity action in distance running. Foot and Ankle 7(4), 197-217.

Submitted: November 19, 2014

Accepted: December 8, 2014 